\title{
Evaluation of anti-oxidant and oxidative stress parameters in chronic obstructive pulmonary disease
}

\author{
Pampareddy B Kollur ${ }^{1}$, Kiran Kumar Akka ${ }^{2, *}$, Basawarajeshwari P Kollur ${ }^{3}$, Sangappa \\ Virupaxappa Kashinakunti ${ }^{4}$
}

\begin{abstract}
${ }^{1,3}$ Associate Professor, ${ }^{2}$ Assistant Professor, ${ }^{4}$ Professor, ${ }^{1,2,4}$ Dept. of Biochemistry, ${ }^{3}$ Dept. of Physiology, ${ }^{1}$ Modern Institute of Medical Sciences, Kanadia, Indore, ${ }^{2}$ M.R. Medical College, Kalaburagi, ${ }^{3}$ Al-Badar Dental College, Kalaburagi, S. Nijalingappa Institute of Medical Sciences, Bagalkot, India
\end{abstract}

*Corresponding Author:

Email: akkakiran@gmail.com

\begin{abstract}
Introduction: Chronic obstructive pulmonary disease (COPD) is an important lung disorder. Tobacco smoking accounts for $80 \%$ of patients of COPD cases and the remaining $20 \%$ are due to exposure to environmental tobacco smoke, occupational dusts and chemicals, and indoor air pollution from biomass fuel used for cooking and heating in poorly ventilated buildings. The oxidative stress seen with COPD patients is due to the oxidants present in cigarette smoke and from increased amounts of reactive oxygen species released from leucocytes, from both in air spaces and blood.

Materials and Methods: This was prospective, case-control study conducted at a tertiary care teaching hospital (medicine department) from April 2015 to August 2015. After obtaining written informed consent a total of 84 participants were explained about the study. The anti-oxidant parameters i.e. Vitamin $\mathrm{C}$ and E, superoxide dismutase, whole blood reduced glutathione and oxidative stress markers i.e. malondialdehyde, serum nitric oxide were measured both in COPD patients and controls. The study was approved by institutional ethics committee. The results are expressed as mean and standard deviation of the parameters evaluated. The unpaired ' $t$ ' test wass used for comparing different biochemical parameters between cases and controls. The $\mathrm{p}$ value of $<0.05$ was considered as statistically significant.

Results \& Discussion: There was no statistically significant difference in the demographic data between the cases and controls. Maximum patients were in stage 3 COPD. Tobacco smoking is an important cause for development of COPD by formation of reactive oxygen species and other free radicals There was statistically significant difference $(\mathrm{p}<0.001)$ in anti-oxidant levels (Vitamin $\mathrm{C}$ and $\mathrm{E}$, superoxide dismutase, Whole blood reduced glutathione) and oxidative stress markers (malondialdehyde, serum nitric oxide) and between cases and controls.

Conclusion: The results of the present study indicate a disturbance in oxidant/antioxidant status in COPD patients. The periodic measurements of oxidative stress markers and antioxidant status in COPD patients might be useful in prognosis of the disease. These results may contribute for the development of novel therapeutic interventions.
\end{abstract}

Keywords: Anti-oxidant, Chronic obstructive pulmonary disease (COPD), Free radicals, Oxidative stress.

Received: $02^{\text {nd }}$ August, 2017

\section{Introduction}

Chronic obstructive pulmonary disease (COPD) is defined as "A disease state characterized by the presence of air flow obstruction due to chronic bronchitis or emphysema; the airflow obstruction is generally progressive, may be accompanied by airway hyper-reactivity, and may be partially reversible". $80 \%$ of patients of COPD cases are due to smoking tobacco, and $20 \%$ have a combination of exposures to environmental tobacco smoke, occupational dusts and chemicals, and indoor air pollution from biomass fuel used for cooking and heating in poorly ventilated buildings. ${ }^{1}$

COPD includes two conditions, chronic bronchitis, a condition of large-airway inflammation and remodeling, and emphysema, disease of the distal airways and lung parenchyma that manifests as loss of surface area for gas exchange. ${ }^{2}$ The oxidative stress seen with COPD patients are from the oxidants present in tobacco smoke and from the increased levels of reactive oxygen species released from leucocytes, from both in air spaces and blood. ${ }^{3}$ Oxidative stress leads to increased concentration of free radicals which can cause damage to the lipids, proteins and nucleic acids (DNA). Polyunsaturated fatty acids (PUFA) present in the cell membrane are also one of the important target of oxidants. ${ }^{4}$

Although there are studies conducted on anti-oxidant levels in COPD patients, the results are not consistent with oxidant parameters and antioxidant levels in the pathogenesis of COPD. ${ }^{5,6}$ Hence the present study was with an objective to know the levels of oxidative stress 
markers (malondialdehyde, serum nitric oxide) and anti-oxidants (Vitamin $\mathrm{C}$ and $\mathrm{E}$, superoxide dismutase, Whole blood reduced glutathione) in patients with COPD.

\section{Material and Methods}

This was prospective, case-control study conducted at a tertiary care teaching hospital (medicine department) from April 2015 to August 2015. The objectives of the study were explained to the participants and informed consent was taken. The study was approved by institutional ethics committee. A total of 84 subjects ( 42 cases and 42 controls) were included in the study. A COPD case was defined according to the criteria of the Global Initiative for Chronic Obstructive Lung Disease accordingly staging of COPD was done. Stage I: Mild COPD; Stage II: Moderate COPD; Stage III: Severe COPD; Stage IV: Very Severe COPD. ${ }^{7}$ Patients were selected form medicine out-patient department and controls were chosen those who had no lung disorders and were nonsmokers. Patients with history of medical disorders which might interfere with results of the study like diabetes, hypertension, renal and hepatic disease and other pulmonary disorders like asthma, patients who had recent surgery were excluded from the study.

\section{Measurement of laboratory parameters}

From each patient $10 \mathrm{ml}$ blood was collected. By centrifugation at $3000 \mathrm{rpm}$ for 10 minutes at room temperature, serum was separated. Analysis was carried out on the samples.

Baker and Frank method for estimation of Serum Vitamin-E: Serum vitamin-E reduces ferric to ferrous ions, which then form a red colored complex with 1 -dipyridyl. Tocopherols and carotenes are first extracted into Xylene and the absorbance is read at $460 \mathrm{~nm}$ to measure the carotenes. A correction for the carotenes is made after adding ferric chloride and reading at 520 $\mathrm{nm}$. Results were expressed as $\mathrm{mg} / \mathrm{dl}$ of vitamin E. $^{8}$

Lowry et al method was used for Serum Vitamin-C level: Vitamin $\mathrm{C}$ was determined by titration method which employs the titration with 2, 6-dichlorophenol indophenol in acid solution. On titration with an ascorbic acid solution, this compound is reduced to the colourless leucobase. The ascorbic acid is oxidized to dehydroascorbic acid. End-point was blue to red to colorless. Milligram of vitamin C / $100 \mathrm{ml}$ of plasma are $1.6 / \mathrm{ml}$ of titration. ${ }^{9}$
Ernest Beutler et al., method was used for measuring whole blood reduced glutathione: the method is based on the development of a relatively stable yellow color, when $5,5^{\prime}$ - dithiobis-(2- nitrobenzoic acid) is added to sulfhydryl compounds. $1.0 \mathrm{ml}$ of blood extract was mixed with $4.0 \mathrm{ml}$ of $0.3 \mathrm{M} \mathrm{Na}_{2} \mathrm{HPO}_{4} 1.0 \mathrm{ml}$ of DTNB reagent [ $40 \mathrm{mg}$ of $5,5^{\prime}$ - dithiobis (2-nitrobenzoic acid) in $100 \mathrm{ml}$ of aqueous $1 \%$ trisodium citrate]. Absorbance was read at $412 \mathrm{~nm}$ immediately. Results were expressed as micromoles/liter. ${ }^{10}$

Marklund and Marklund method was used for measuring serum superoxide dismutase (SOD) activity. SOD activity was determined by use a simple and rapid method, based on the ability of the enzyme to inhibit the autoxidation of pyrogallol. The autoxidation of pyrogallol in the presence of EDTA in the $\mathrm{pH} 8.2$ is $50 \%$. The principle of this method is based on the competition between the pyrogallol autoxidation by $\mathrm{O}_{2}^{-}$and the dismutation of this radical by SOD. ${ }^{11}$

Serum Nitric oxide (NO) as nitrite was measured by method described by Najwa Cortas and Nabil Wakid. The oxidation products of $\mathrm{NO}$, nitrite $\left(\mathrm{NO}_{2}{ }^{-}\right)$and subsequently nitrate $\left(\mathrm{NO}_{3}{ }^{-}\right)$, serve as an index of NO production. The method for measuring plasma nitrite and nitrate levels was based on the Griess reaction. Samples were initially deproteinized with Somogyi reagent. Total nitrite (nitrite+nitrate) was measured by spectrophotometry at $545 \mathrm{~nm}$ after conversion of nitrate to nitrite by copperized cadmium granule. A standard curve was established from nitrite standards to analyze unknown sample concentrations. Results were expressed as micromoles/liter. ${ }^{12}$

Kei Satoh Method was used for measuring serum malondialdehyde. MDA is being extensively used in assessing the process of lipid peroxidation. Reactive Oxygen Species (ROS) generated causes peroxidation of Polyunsaturated Fatty Acids (PUFA) of the cell membranes. Serum Lipid peroxide was measured by precipitating lipoporoteins with trichloroacetic acid and boiled with thiobarbituric acid which reacts with Malondialdehyde to get pink colour. ${ }^{13}$

\section{Statistical Analysis}

The results are expressed as mean \pm SD of the various parameters measured. SPSS software (2013 version) was used for statistical analysis. For comparing different biochemical parameters between cases and controls, unpaired ' $t$ ' test was used. The difference was considered significant if the $\mathrm{p}$ value was $<0.05$. 


\section{Results}

A total of 84 subjects ( 42 cases and 42 controls) were included in the final analysis. The demographic data is shown in table 1 . There was no statistically significant difference in the demographic data between the cases and controls. Maximum patients were in stage 3 COPD. The anti-oxidant and oxidative stress marker levels between the cases and controls is shown in table 2. There was statistically significant difference in anti-oxidant status and oxidative markers between cases and controls.

Table 1: Demographic data and the pulmonary function tests of cases and controls Variable Cases Controls P value

Age $48.97 \pm 2.3245 .24 \pm 2.12 \mathrm{NS}$

Sex (Male /Female) 34/8 29/13 NS

BMI 29.3 $\pm 1.827 .5 \pm 1.5 \mathrm{NS}$

Smokers/ex-smokers 31/13 - -

COPD stage

I 03 - -

II 07 - -

III 29 - -

IV 03 - -

$\mathrm{NS}=$ Not significant

Table 2: Anti-oxidant and oxidative stress levels between the cases and controls Parameter Cases Controls $P$ value

Vitamin C (mg/dl) $0.52 \pm 0.061 .46 \pm 0.14$ $<0.001$

Vitamin E $(\mathrm{mg} / \mathrm{dl}) 0.95 \pm 0.081 .59 \pm 0.21$

$<0.001$

SOD $(\mathrm{U} / \mathrm{ml}) 4.94 \pm 0.748 .87 \pm 1.58<0.001$

GSH $(\mathrm{mg} / \mathrm{dl}) 27.48 \pm 1.9318 .27 \pm 1.46$

$<0.001$

MDA $(\mu \mathrm{mol} / \mathrm{ml}) 5.72 \pm 1.292 .54 \pm 1.43$

$<0.001$

Serum NO $(\mu \mathrm{mol} / \mathrm{L}) 112.97 \pm 10.5626 .45 \pm$ $5.92<0.001$

SOD $=$ Superoxide dismutase, GSH $=$ Whole blood reduced glutathione, MDA = Malondialdehyde, $\mathrm{NO}=$ Nitric oxide.

\section{Discussion}

Tobacco smoking is an important cause for development of COPD caused mainly due to reactive oxygen species and lesser extent due to other free radicals. ${ }^{14}$ Free radicals act on polyunsaturated fatty acids (PUFA) present on cell membrane and are responsible for lipid peroxidation, as measured by MDA which is used widely as a sensitive marker of lipid peroxidation. In the present study, there was statistically significant $(\mathrm{P}<0.001)$ difference in
MDA levels between the cases and controls (table 2). Similar findings have been reported by other studies. ${ }^{15-18}$

Nitric oxide oxidation products are important inflammatory mediators in COPD. ${ }^{19}$ Diseases of the pulmonary system such as COPD are characterized by an increased expression of nitric oxide synthase- $2 .{ }^{20}$ In the present study, a statistically significant difference $(p<0.001)$ was seen in serum nitric oxide levels between the cases (table 2). Similar findings are reported by other studies. ${ }^{21-22}$ We did not find other studies which measured serum nitric oxide, but they measured exhaled nitric oxide. Overall there was statically significant difference in oxidative stress levels (MDA and serum nitric oxide levels) between the cases and controls.

The anti-oxidant status as measured by Vitamin C and E, Whole blood reduced glutathione and superoxide dismutase showed statistically significant difference between cases and controls (table 2). Vitamin $\mathrm{E}$ is major antioxidant, it protects PUFA from oxidative damage, in addition has anti-inflammatory function, plays a role in maintenance of integrity and fluidity of plasma membranes. ${ }^{23}$ Similar findings of significant difference of Vitamin $\mathrm{E}$ levels between cases and controls have been reported by other studies..$^{21,24,25}$

A statistically significant difference was also seen with Vitamin C levels between the cases and controls, two reasons postulated are, tobacco smoke stimulates lipid peroxidation in lung that is reduced by vitamin $\mathrm{C}$ and vitamin $\mathrm{C}$ is required to regenerate vitamin $\mathrm{E}$, similar findings with Vitamin C are reported in other studies..$^{26-28}$ One of the important scavengers of super oxide radical is Superoxide dismutase (SOD). The decreased levels of SOD play an important role in the pathogenesis of COPD. ${ }^{27}$ In the present study, COPD patients had statistically significant decreased level of Superoxide dismutase when compared with controls ( $\mathrm{P}$ value < 0.001)). Similar findings with Superoxide dismutase have been reported by other studies. ${ }^{17,27}$

There was a statistically significantly difference in whole blood reduced glutathione levels between the cases and controls. Normally, most of the intracellular glutathione is stored in the reduced form and during oxidative stress, the free sulfhydryl (- $\mathrm{SH})$ groups become oxidized resulting in loss of reduced form. The tobacco smoke (gaseous phase) may also irreversibly react with reduced form (GSH) to form derivatives of GSH, thereby depleting the total available GSH pool. ${ }^{29}$ Other studies have also reported similar findings. ${ }^{30,31}$ 


\section{Limitations of the study}

The study was conducted at a single center, we did not include spirometry readings (for pulmonary function tests) and the sample size was small. We did not measure oxidative stress parameters and anti-oxidant status in COPD phenotypes (Chronic bronchitis and Emphysema). There exists evidence for the role of oxidative stress in the pathogenesis of emphysema, mainly in animal studies. ${ }^{32}$ Future studies should multi-centric, include large sample size and measure parameters in COPD phenotypes.

\section{Conclusion}

The present study revealed that levels of free radicals and oxidative stress markers had shown statistically significant disturbance in the form of increase levels of whole blood reduced glutathione, malondialdehyde, nitric oxide and decreased levels of Vitamin C, Vitamin E, superoxide dismutase among the cases of COPD. The measurement of oxidative stress markers and antioxidant status at regular intervals in COPD patients might be useful in prognosis of the disease. These results may contribute for the development of novel therapeutic interventions. Future research should be directed to know whether anti-oxidant supplementation along with other standard treatments for COPD will significantly alter the prognosis of the disease.

Acknowledgement: We authors thank the subjects who participated in the study.

\section{Conflict of interest: None}

\section{References}

1. Mephie SJ, Papadakis MA, Lawrence MT. Current medical diagnosis and treatment. $47^{\text {th }}$ edition, McGraw Hill Medical Publisher, New Delhi, 2008;pp. 216-21

2. Tuder RM, Petrache I. Pathogenesis of chronic obstructive pulmonary disease. J Clin Invest 2012; 122:2749-55.

3. Rahman I, Adcock IM. Oxidative stress and redox regulation of lung inflammation in COPD. Eur Respir J 2006;28:219-42.

4. Bast A, Haenen GR, Doelman CS. Oxidants and antioxidants. Am J Med 1991;91:2-13S.

5. Kluchová Z, Petrásova D, Joppa P, Dorková Z, Tkácová $\mathrm{R}$. The association between oxidative stress and obstructive lung impairment in patients with COPD. Phys Res 2007;56:51-6.

6. Mak JCW. Pathogenesis of COPD. Part II. Oxidative-antioxidative imbalance. Int J Tuberc Lung Dis 2008;12:368-74.

7. Global initiative for chronic obstructive lung disease. Available from
http://www.who.int/respiratory/copd/GOLD_WR _06.pdf. Last accessed on $24^{\text {th }}$ May 2017 at $4 \mathrm{pm}$

8. Baker $\mathrm{H}$ and Frank O; Determination of serum $\alpha$ -tocopherol. In Varleys Practical Clinical Biochemistry, 6th edition London, Gokenlock AH., Me Murray JR., Mehauchian DM 1968;9023.

9. Varley H. Determination of plasma ascorbate by 2,6- Dichlorophenolindophenol titration. In "Varley's Practical Clinical Biochemistry" Ed: Gowenlock AH, McMurray JR and McLauchlan DM, Heinemann Medical Books, London 1988; Vol. I; 6 TH edition; Chapter 35:927.

10. Beutler E, Duron O, Kelly BM. Improved method for the determination of blood glutathione. J Lab Clin Med 1963;61(5):882-8.

11. Marklund S, Marklund G. Involvement of the superoxide anion radical in the autoxidation of pyrogallol and a convenient assay for superoxide dismutase. Eur J Biochem 1974;47(3):469-74.

12. Najwa K. Cortas and W. Wakid. Determination of inorganic nitrate in serum and urine by kinetic cadmium reduction method. Clin Chem 1990;3618:1440-3.

13. Estimation of lipid peroxide (MDA) by Kei satoh method. Clinica Chemica Acta 1998;90:37-43.

14. 14 Gerritsen, W.B., Asin, J., Zanen, P., Bosch van de, J.M.M., Haas, F.J.L.M. Markers of inflammation and oxidative stress in exacerbated chronic obstructive pulmonary disease patients. Respir Med. 2005;99:84-90.

15. Papaioannoou AI, Mazioti A, Kiropoulos T, Tsilioni I, Kotsokera A, Tanou K et al., Systemic and airway inflammation and presence of emphysema in patients with Chronic Obstructive Pulmonary Disease. Respir Med 2010;104:27582.

16. Boschetto P, Quintavalle S, Zeni E, Leprotti S, Potena A, Ballerin L et al., Association between markers of emphysema and more severe Chronic Obstructive Pulmonary Disease. Thorax. 2006;61:1037-42.

17. Kirkil G, Muz. MH, Seckin D, Sahin K, Kucuk O. Antioxidant effect of Zinc picolinates in patients with Chronic Obstructive Pulmonary Disease. Respir Med 2008;102:840-4.

18. Isik B, Isik SR, Yolacan H, Isik MR. Serum Malondialdehyde and Paraoxonase levels in Chronic Obstructive Pulmonary Disease. Turkish Respir J 2005;6(1):19-21.

19. Kanazawa, Shoji, Yoshikawa, Hirata. Increased production of endogenous nitric oxide in patients with bronchial asthma and COPD. Clinical and Experimental Allergy 1998;28(10):1244-50.

20. DC. Chambers, W.S. Tunncliffe. Acute inhalation of cigarette smoke increases nitric oxide concentration. Thorax 1998:53:677-9.

21. Rout A.M, Suryakar AN. Study of oxidative stress relation with antioxidant status in chronic bronchitis. Intr. J Public Health Sci 2012;1(1):710.

22. Rupali S Pawar, Subhodhini A Abhang, Damgaye TM, Rahul Lokhande. Study of oxidative / nitrosative stress, non-enzymatic antioxidants and markers of airflow obstruction (fev1 \% predicted) in chronic obstructive pulmonary disease (copd) patients. Int J Bioassays 2014;3(06):3092-100. 
23. Bilacom HMO, Grant BJB, Muti P, Sempos CT, Frendenheim JL, Browne RW, et al. Antioxidant, oxidative stress and pulmonary function in individuals diagnosed with asthma or COPD. European J Clin Nutri 2006;60:991-9.

24. Tug T, Karatas F, Terzi SM; Antioxidant vitamins (A, C and $\mathrm{E}$ ) and malondialdehyde levels in acute exacerbation and stable periods of patients with chronic obstructive pulmonary disease. Clin Invest Med 2004;27(3):123-8.

25. Daga MK, Chhabra R, Sharma B, Mishra TK.; Effects of exogenous vitamin E supplementation on the levels of oxidants and antioxidants in chronic obstructive pulmonary disease. J Biosci 2003;28(1):7-11.

26. Sargeant LA, Jaeckel A, Wareham NJ. Interaction of vitamin $\mathrm{C}$ with the relation between smoking and obstructive airway disease in EPIC Norfolk. Eur Respir J 2000;16:397-403.

27. Rai RR, Phadke MS. Plasma oxidant-antioxidant status in different respiratory disorders. Indian J Clin Biochem 2006;21(2):161-4.

28. Calikoglu M, Unlu A, Tamer L, Ercan B, Bugdayci R, Atik U et al., The levels of serum vitamin $\mathrm{C}$, malondialdehyde and erythrocyte reduced glutathione in Chronic Obstructive Pulmonary Disease and in healthy smokers. Clin. Chem Lab Med.2002;40(10):1028-31.

29. Toorn MV, Maria P, Varies S, Slebos D, Bruin HG, Abello N, et al. Cigarette smoke irreversibly modifies glutathione in airway epithelial cells. Am j Physiol Lung Cell Mol Physiol 2007;293:L1156-L1162.

30. Nagaraj, Pyati A, Murthy S. Oxidative stress and antioxidant status in COPD patients. Intr. J of Pharm and Biol Sci 2011;11(4):447-56.

31. Rahman I, MacNee W. Oxidant/antioxidant imbalance in smokers and chronic obstructive pulmonary disease. Thorax 1996;51:348-50.

32. Tuder RM, Zhen L, Cho CY, TarasevicieneStewart L, Kasahara Y, et al. Oxidative stress and apoptosis interact and cause emphysema due to vascular endothelial growth factor receptor blockade. Am J Respir Cell Mol Biol 2003;29:8897. 